\title{
Proposal of sheet buckling design criteria for high strength steel under impact crushing
}

\author{
K. Watanabe ${ }^{1}$, K. Natori ${ }^{2}$, H. Enjoji ${ }^{2}$, T. Tanaka ${ }^{3} \&$ Y. Imaida ${ }^{3}$ \\ ${ }^{1}$ Kobe Steel, Ltd., Japan \\ ${ }^{2}$ Graduate School of Engineering, Doshisha University, Japan \\ ${ }^{3}$ Faculty of Science and Engineering, Doshisha University, Japan
}

\begin{abstract}
The purpose of this study is to verify the validity of sheet buckling design based on the effective width theory as an investigation of the impact crushing properties in high strength steel sheets. The need to make full cross-sections effectively without elastic buckling occurring is clarified and the application of the effective width theory under high speed deformation is considered. The findings of this investigation into the sheet buckling phenomenon are reported with numerical simulation by varying deformation strain rate, mechanical property of material and member configuration. The results demonstrate that the constant $\alpha$ used in the existing theory is function of strain rate $\dot{\varepsilon}$ and material yield stress $\sigma_{Y}$. With increasing crush speed, the cross section of a steel sheet becomes effective; the design based on the existing theory has provided enough evidence of safety. Furthermore, some criteria for limit buckling design are proposed.
\end{abstract}

Keywords: impact crushing property, sheet buckling behaviour, effective width theory, elastic buckling, buckling analysis, high strength steel, strain rate dependence, design criteria, crash safety, thin walled member.

\section{Introduction}

In recent years, along with the trend of the low carbon society towards earth environment protection, the improvement in fuel consumption of the automobile has been strongly needed. Therefore, adopting high strength steel sheets as the material of automobile body construction has contributed to both weight reduction of the body and improvement in safety [1]. 
In particular, high strength steel sheets are used to make thin walled box section members for impact absorption in the event of an automotive crash through their plastic deformation $[2,3]$. The member is designed to function effectively within a narrow deformation range. However, the buckling collapse may occur by elastic buckling before the full section of a member is yielded. In this case, the consensus is that the impact absorption member does not act efficiently, and the strength of the member is not obtained as expected even if the materials were developed into high strength. Therefore the thin walled member is conventionally designed based on von Karman's effective width theory [4].

Meanwhile, it is said that strain rate affected materials reach $1000 / \mathrm{sec}$ at the time of crash [5]. This is 1 million times larger than the static strain rate establishing the theory, and has some concerns that unique property appear compared to quasi-static deformation behaviour. In previous research, the dependence of the theory on strain rate had been reported on the condition of low speed range only [6]. It has not clarified that the application of the effective width theory is limited to impact deformation and is required that something be modified. In addition, technological recent trends and interest is replacement of materials giving various work hardening properties, developed into high strength and thinning of members. It is necessary to consider the effect of these things on the theory.

Then, the purpose of this study is to clarify buckling phenomena typically found in thin plates under dynamic deformation. The influence of crush speed and material mechanical properties on the effective width theory is investigated.

\section{Theory}

\subsection{Elastic sheet buckling and effective width}

An impact absorption member functions effectively by deforming plastically after uniform compression until the full section is yielded. However, a member may be buckled before the material has yielded in some conditions, in what is known as elastic buckling. If the configuration of the specimen is thin plate, nonlinearly distributed axial stress occurs in the cross section after out-of-plate deformation (see fig. 1). After occurrence of elastic buckling, the crush load has concentrated gradually on the edges of plate, and the thin plate buckled plastically when the stress at edge reached yield point.

Theoretical critical elastic buckling stress on elastic perfectly plastic solid (Young's modulus $E$, Poisson's ratio $v$ ) is given by the following equation [7].

$$
\sigma_{c r}=\frac{k \pi^{2} E}{12\left(1-v^{2}\right)}\left(\frac{t}{w}\right)^{2}
$$

$k$ is the buckling coefficient that is determined by support conditions and plate aspect ratio.

Then, it assumes that the non-linear axial stress distribution in the centre is accumulated in both side edges as shown in fig. 1 to being equal to resultant 
force. Thus, stress distribution can be linearly-simplified. In fact, this process means that the entire load is regarded to provide at both side edges $[7,8]$. The supposed width is called the effective width $b_{e}$, i.e. given by

$$
b_{e}=\frac{\int_{0}^{w} \sigma(x) d x}{\sigma_{\text {edge }}}
$$

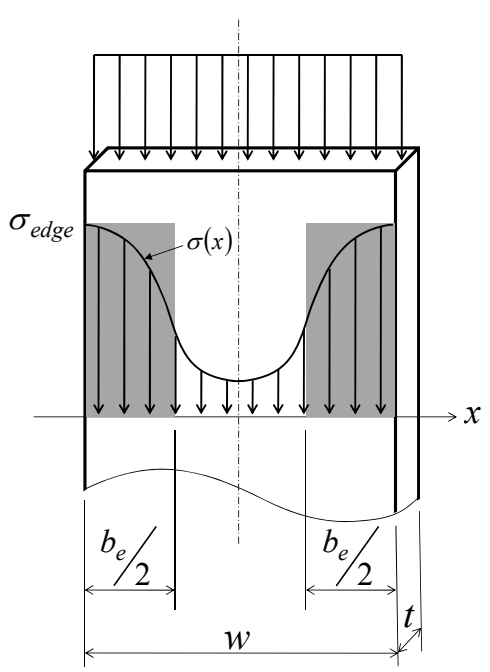

Figure 1: Description of axial stress distribution in sheet buckling.

\subsection{Effective width theory [9]}

Von Karman's effective width theory is the simplified theoretical technique for estimation of the timing of collapse after elastic buckling by positing a few premises. First, with accompanying deformation, it is visualized that the supposed plate has a breadth with an effective width calculated from nonlinear axial stress distribution. And secondly, it is assumed that buckling collapse occurs when the theoretical critical elastic buckling strength of the supposed plate reaches the yield strength of its material with narrowing effective width $\left(\sigma_{c r}=\sigma_{Y}, w=b_{e}\right)$.

Thus, if the mechanical property of the material is ideal elastic-plastic, i.e. elastic perfectly plastic solid, the effective width as of then is derived from a following equation according to eqn. (1).

$$
b_{e}=\alpha \cdot \frac{t \sqrt{E}}{\sqrt{\sigma_{Y}}}
$$

provided that,

$$
\alpha=\frac{\pi \sqrt{k}}{\sqrt{12\left(1-v^{2}\right)}}
$$

Substituting mechanical properties of steel into eqn. (1), the constant $\alpha$ is 1.9. 


\subsection{Buckling design}

The basic configuration of most impact absorption member has a cross-section that is hat-like or rectangle tube, and assembles longitudinally along the automobile body, in order to absorb the crash load from the front. Since corners and side edges of such configuration are resistant to buckling, these can provide the crash load. It is apparent that there is a risk of elastic buckling occurrence with an increasing in width at other parts, e.g. straight-line section.

In order to prevent elastic buckling, it is required that the axial stress distribution does not become nonlinear, thus, the effective width corresponds with the breadth of plate. Thereby, to determine the width of a straight-line to stay within the effective width $b_{e}$ given by eqn. (3) is regarded as a design guide. It is generally designed on the safe side using the constant $\alpha$ under present circumstances.

\section{Numerical analysis}

\subsection{Analysis condition}

Numerical analysis was performed using nonlinear dynamic explicit finite element code, LS-DYNA. A finite element model of sheet material is applied shell elements in complete integral type. Figure 2 depicts the geometry of analysis object and its boundary conditions. Plate width $w$ and thickness $t$ is varied with fixed axial length $H$. Ideal elastic-plastic that is simulated 590MPa and $980 \mathrm{MPa}$-class high strength steel is applied as the mechanical property of the material (table 1). The compression strain rate is from $0.01 / \mathrm{sec}$ to $5 / \mathrm{sec}$.

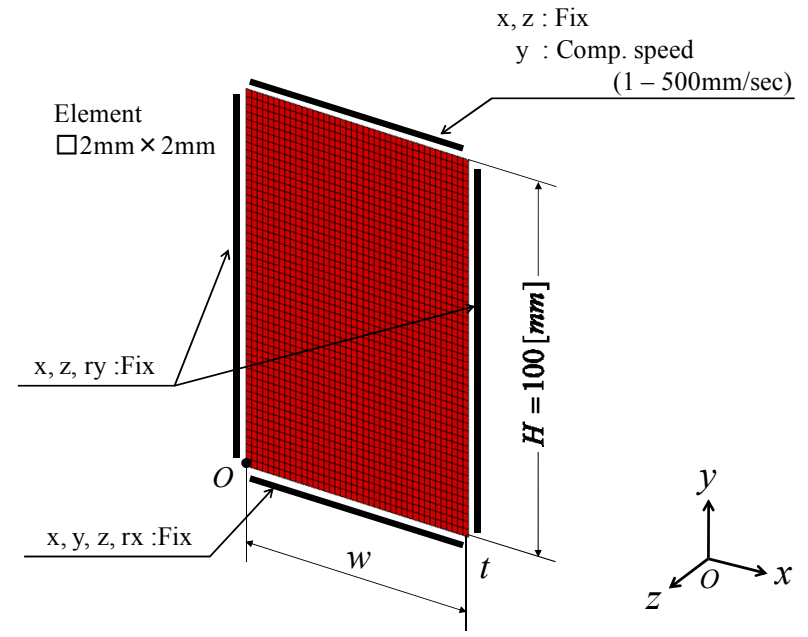

Figure 2: Schematic analysis conditions. A node at $x=w / 2, y=H / 5$ is shifted $z=+0.0001[\mathrm{~mm}]$ as initial imperfection in order for buckling to occur in simulation. 
Table 1: Mechanical properties applied simulation model. The strain rate dependence of dynamic flow stress is not considered.

\begin{tabular}{|c|c|c|c|}
\hline $\begin{array}{c}\text { Elastic } \\
\text { perfectly } \\
\text { plastic }\end{array}$ & $\begin{array}{c}\text { Yield stress } \\
{[\mathrm{MPa}]}\end{array}$ & $\begin{array}{c}\text { Young's } \\
\text { modulus } \\
{[\mathrm{GPa}]}\end{array}$ & $\begin{array}{c}\text { Poisson's } \\
\text { ratio }\end{array}$ \\
\hline 590MPa class & 373 & 210 & 0.3 \\
\hline 980MPa class & 695 & 210 & 0.3 \\
\hline
\end{tabular}

\subsection{Evaluation method [10]}

The effective width just before buckling collapse is calculated from eqn. (2), substituting the axially averaged stress distribution. In the following sentences, this index is simply called "the effective width". Using this index, the effectiveness of cross-section can be evaluated, and then, the validity of sheet buckling design based on the effective width is verified. The moment before a part of the plate begins to yield with a dropping crush load is defined as buckling collapse.

\section{Results and discussion}

\subsection{Buckling phenomenon of thin plate}

The crush load curve at $0.01 / \mathrm{sec}$ when width-thickness ratio $w / t$ is varied as a parameter is shown in fig. 3. The result indicates that elastic buckling stress and absorbed energy increases with decreasing $w / t$. And it is found that there are three types of buckling phenomena following changes on the boundary " $<$ " and " $\triangleleft$ ".

[A] Weakening the centre of the plate by folding up into concertinas.

[B] Excessively bending and yielded when elastic compression is liberated by buckling.

[C] Buckled after deformation of full cross section plastically.

Transition of axial stress distribution, max plastic strain and max deflection indicating the characteristics of each buckling phenomenon is shown in fig. 4 . Elastic buckling occurred at point "P", and then, plastic buckling and collapse occurred at point "Q". Phenomenon A is known as elastic buckling typically found in thin plate, and such increasing crush load after end to rise in load elastically is also the feature of sheet buckling. And, phenomenon $\mathrm{C}$ implies the condition of a full effective section that makes it possible to absorb impact with full mechanical properties of material. Phenomenon B is shown in grey.

Then, withstanding the load of thin plate is verified. Association between elastic buckling stress and sheet buckling phenomenon is shown in fig. 5. When elastic buckling occurs, the buckling stress is independent of material strength. Therefore, it means that increasing the yield strength of the material is no use for increasing the compressive strength of the plate. On the other hand, it is shown that yield strength might obtain the withstand load even if the buckling is phenomenon B. 

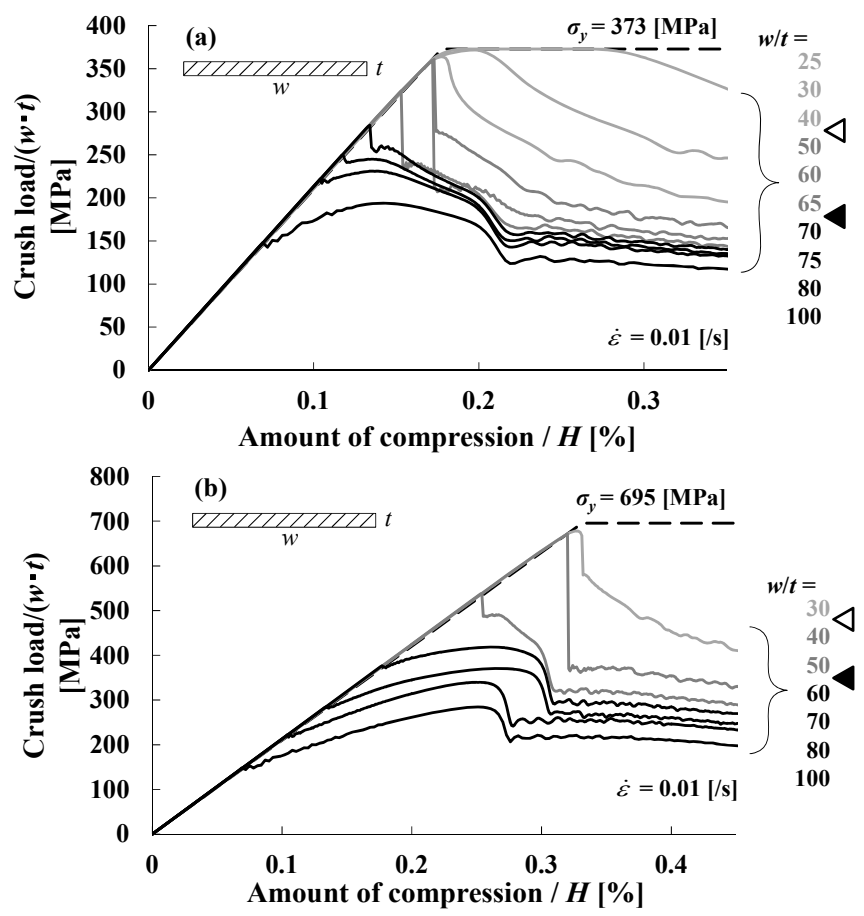

Figure 3: Influence of specimen dimensions on buckling phenomenon under static deformation. (a) $590 \mathrm{MPa}$ class, (b) $980 \mathrm{MPa}$ class.

\subsection{Buckling under impact crush}

The influence of crush speed on buckling phenomenon is considered. The tendency toward varying $w / t$ under dynamic deformation is similar to the case of fig. 3 at static. However, the possibility of developing phenomenon $\mathrm{A}$ is reduced under impact crush.

Crush stress curves when compression speed is varied as a parameter in the same configuration is shown in fig. 6 . The result indicates that the full section become effective with increasing compression speed, and corresponds with empirical rule. Three types of phenomena are seen as well.

\subsection{Relation between effective width and buckling phenomenon}

\subsubsection{Static crush}

The effective width $b_{e}$ calculated from the results in conditions of fig. 3(a) is shown in fig. 7, added design criterion based on the effective width theory.

As shown in this figure, the effective width in the case of phenomenon $A$ gives a constant value $\left(b_{e} / t\right)^{*}$. And, in the case that the plate dimension is less than $\left(b_{e} / t\right)^{*}$, phenomenon B or C occurs. Even though the effective section does 

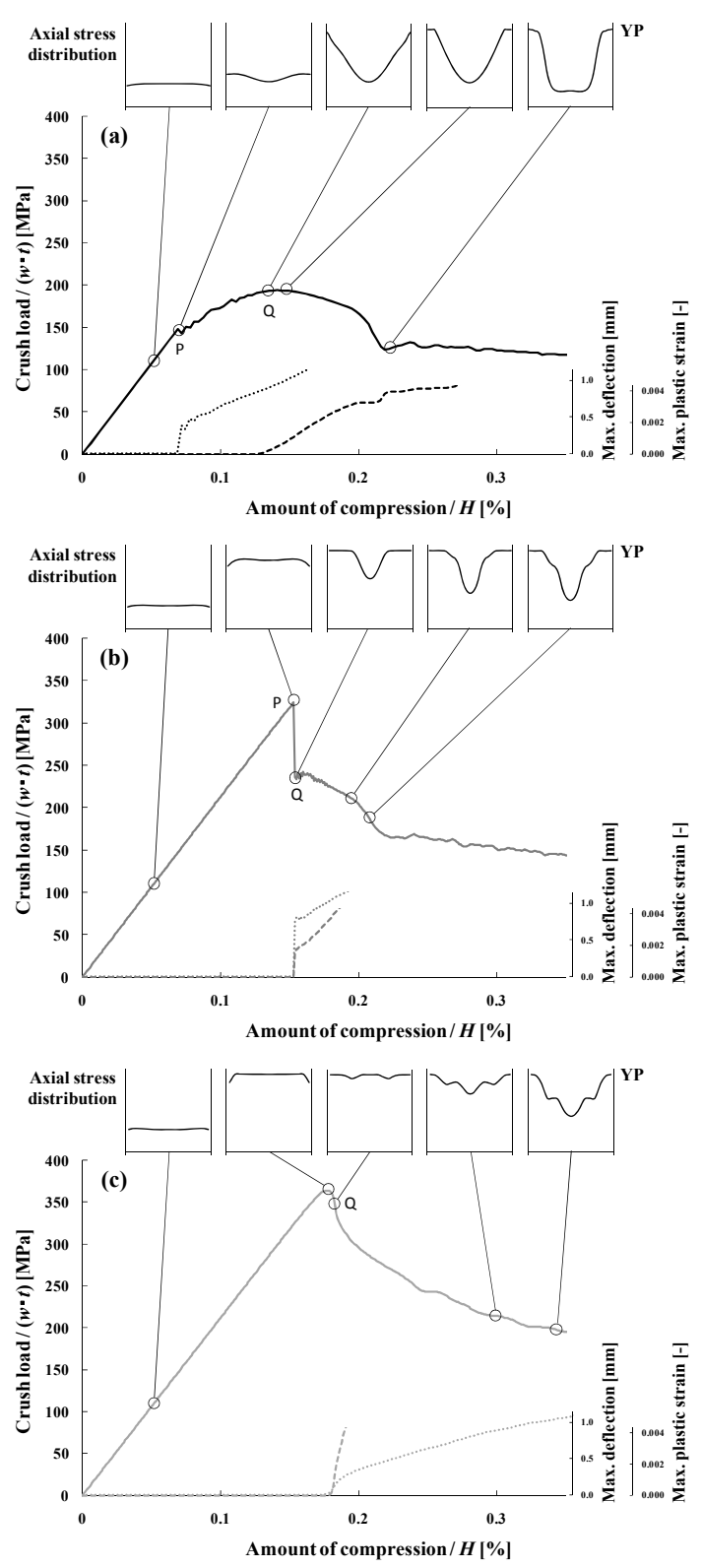

Figure 4: Transition of axial stress distribution indicating the characteristics of each buckling phenomenon. In the case of $590 \mathrm{MPa}$ class material, (a) phenomenon A $(w / t=100)$, (b) phenomenon B $(w / t=65)$, (c) phenomenon $\mathrm{C}(w / t=40)$ at $0.01 / \mathrm{s}$. - ; crush load curve, $\cdots \cdots$; max deflection, - - -; max plastic strain. 


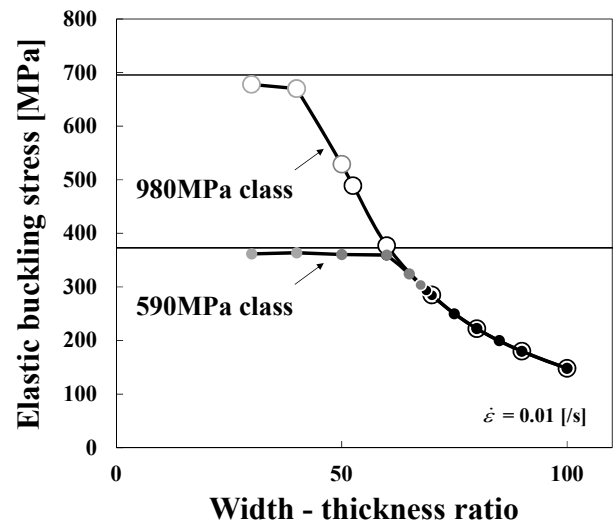

Figure 5: Association between withstand load and sheet buckling phenomenon. Black markers; phenomenon A, dark grey markers; phenomenon $\mathrm{B}$, light grey markers; phenomenon $\mathrm{C}$.
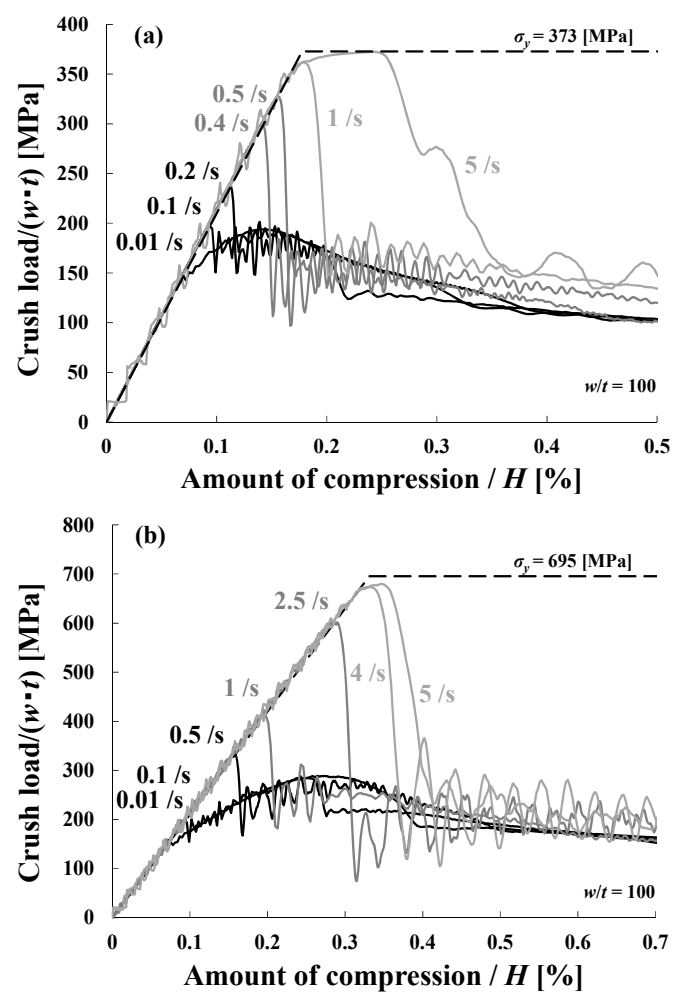

Figure 6: Influence of compression speed on buckling phenomenon. (a) 590MPa class, (b) $980 \mathrm{MPa}$ class. 
not strictly imply full section, the effective width in the case of phenomenon B shows full breadth because plastic deformation occurs soon after deflection.

Figure 7 provides two things. Firstly, at static compression, the design based on measured effective width corresponds to the boundary between phenomenon $A$ and B (see point " $X$ " in fig. 7). Thus, the occurrence of elastic buckling can be avoided by setting the plate breadth to the effective width or lower. Secondly, the design based on the effective width theory corresponds to the boundary between $\mathrm{B}$ and $\mathrm{C}$ (See point "Y" in fig. 7). It is verified that the existing theory is built on at static compression.

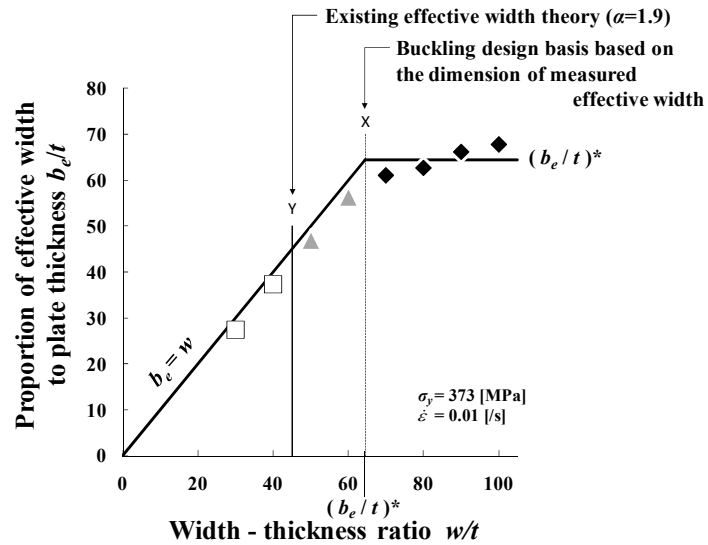

Figure 7: Dependence of effective width on rectangle section aspect ratio. phenomenon $\mathrm{A}, \Delta$; phenomenon $\mathrm{B}, \square$; phenomenon $\mathrm{C}$.

\subsubsection{Impact crush}

Next, the effective width $b_{e}$ calculated from the results in conditions of fig. 6(a) is shown in fig. 8. The effective width in the case of phenomenon A gives a constant value without deformation speed dependence. And the effective width is equal to almost plate breadth on the boundary resulting in a certain compression speed like step function.

In addition, grouping the association between buckling phenomenon and the member configuration for crush speed is shown in fig. 9. As shown in the foregoing, the measured effective width at collapse after the occurrence of elastic buckling (top-left area indicated by the " boundary between phenomenon $\mathrm{A}$ and $\mathrm{B}$ at static (on line " $\mathrm{X}$ " in fig. 9), a constant value without deformation speed and member dimension dependence. 


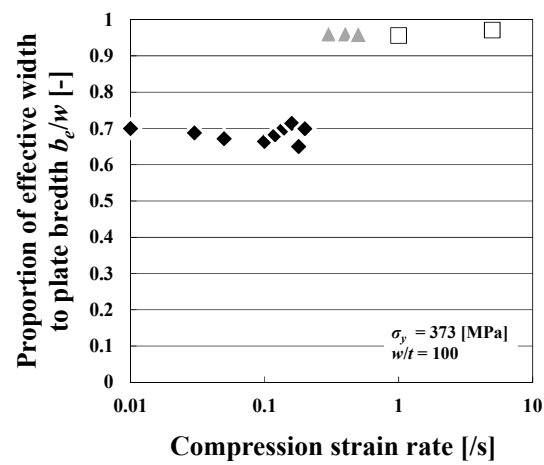

Figure 8: Dependence of effective width on crush speed. $\diamond$; phenomenon A, $\triangle$; phenomenon $\mathrm{B}, \square$; phenomenon $\mathrm{C}$.

On the other hand, with increasing deformation speed, the boundary of phenomena is soaring, and, the range of acceptable dimension become widely. This indicates that elastic buckling may not occur in case of dynamic deformation even if the breadth of plate is larger than the effective width at collapse, i.e. even if the non-linear axial stress distribution occurs.

Thereby, the measured effective width at collapse does not related to the buckling phenomenon at impact crush. And, the design based on the existing effective width theory (on line "Y" in fig. 9) is safe enough at whole range of deformation speed.
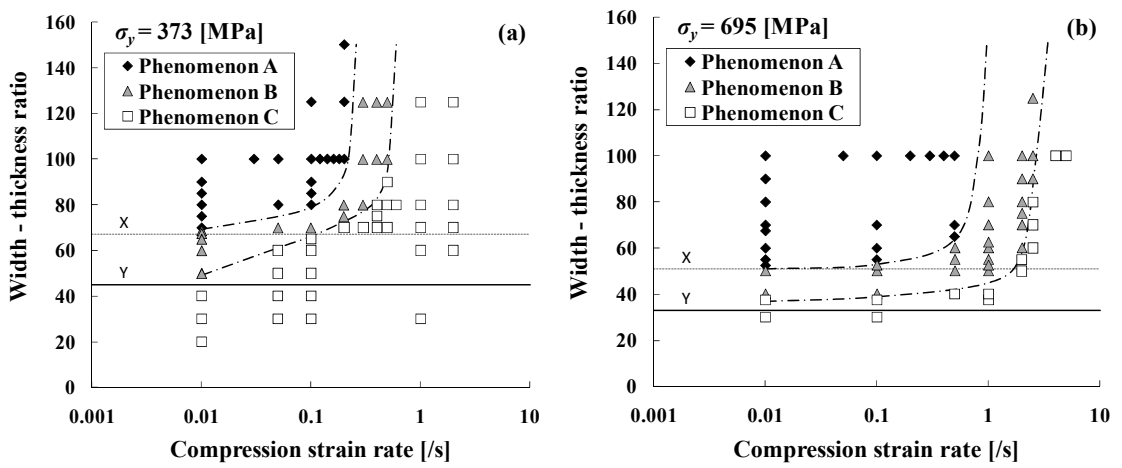

Figure 9: Association between sheet buckling phenomenon and various crush conditions. (a) 590MPa class, (b) $980 \mathrm{MPa}$ class. - - - $\mathrm{x}$; criterion for buckling design based on the measured effective width, - $-\mathrm{y}$; existing effective width theory $(\alpha=1.9),-\cdot-$; boundaries of the occurrence of each buckling phenomenon. 


\subsection{Approach of buckling design}

While it is demonstrated that the design based on the existing theory is safety side, a possibility of limit design remains a consideration. Three steps for limit design can be proposed as follows using figs. 5 and 9.

$>$ Prevent the occurrence of elastic buckling.

$>$ Full section function effectively.

$>$ Withstand load up to yield strength.

As shown in fig. 10, these limit design criteria are expressed by correcting the constant $\alpha$ in eqn. (3) in the effective width theory. It is clarified that the coefficient $\alpha$ depend on compression stain rate $\dot{\varepsilon}$ and yield stress of material $\sigma_{Y}$.

$$
\alpha=\alpha\left(\dot{\varepsilon}, \sigma_{Y}\right)
$$

The sensitivity of $\alpha$ against $\sigma_{Y}$ is negligible at static loading. On the other hand, the coefficient $\alpha$ does depend on the yield stress of the material when the assumed strain rate is high. In the case of dynamic loading, we have to take account of this fact in order to design the energy absorption member as light as possible.

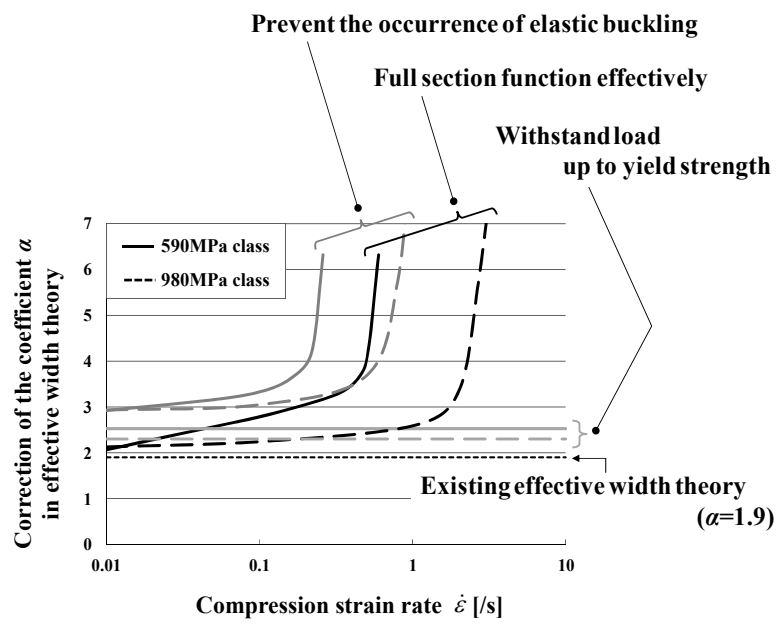

Figure 10: Criteria for limit design. If the crush conditions are below or right the line, the design can be secured at each safety level.

We proposed the possibility of new design criteria that can reduce the thickness of plates or increase the width of those by a dozen times compared to the existing criteria at the time of an automobile crash, i.e. strain rate 1000/sec. In the existing design of the automobile in order to exert energy absorbing performance effectively, the cross-section shape of members is devised by press forming to add concavo-convex for increasing the number of edges and dividing the straight breadth. It is expected that the analytical facts demonstrated in this paper promote the weight saving and simplification of energy absorption 
component configuration. These improvements may also provide shortening of the forming process and stabilization of forming.

\section{Conclusion}

In this study, the validity of the sheet buckling design based on the effective width theory under high speed deformation as an investigation of impact crushing properties of high strength steel sheets is verified. Using numerical simulation for a thin plate model, the sheet buckling phenomena are observed in a wide range of crush stain rates. The results are as follows.

1) Buckling phenomena depend on the dimensions of the cross-section member and crush strain rate, and, can be divided into three types.

2) It is clarified that the constant $\alpha$ used in the existing effective width theory is a function of the crush strain rate and material yield stress. In more dynamic deformation, the cross-section becomes effective, while the dependence of $\alpha$ on material mechanical properties increases.

3) The design based on the existing theory provides enough evidence of safety. Some criteria for limit buckling design are proposed, for example, whether the occurrence of elastic buckling can be prevented, whether the full section can function effectively, and whether the crush load can be withstood up to yield strength.

\section{References}

[1] Sugiyama, T., Journal of Japan Society for Technology Plasticity, 46(534), pp. 552-555, 2005.

[2] Furusako, S., Uenishi, A., Miyazaki, Y., Shinnittetsu giho, 385, pp. 32-35, 2006.

[3] Oogusu, H., Hara, K., Nisshin Steel Technical Report, 88, pp. 46-54, 2007.

[4] Setiyono, H., International Journal of Mechanical Sciences, 50(8), pp. 1280-1291, 2008.

[5] Mukai, Y., Watanabe, K., Kobe Steel Engineering Report, 52(3), pp. 3234, 2002.

[6] Kassar, M., Pan, C.L., Yu, W.W., Journal of Structure Engineering, 118(11), pp. 3151-3168, 1992.

[7] Furusu, K., Tsurumi, Y., Nakagawa, T., Takagi, J., Proceedings of 14th Design \& Systems Conference of JSME, 46, pp. 344-347, 2004.

[8] Noma, K., Muguruma, T., Takada, K., Taura Technical Review, 34, pp. 8-15, 2008.

[9] Hasegawa, A., Usami, T., Proceedings of JSCE, 315, pp. 157-160, 1981.

[10] Natori, K., Watanabe, K., Tanaka, T., Imaida, Y., Key Engineering Materials, 473, pp. 376-381, 2011. 